\title{
Effect of intravenous insulin infusion on mortality among diabetic patients after myocardial infarction
}

\author{
DJ GWILT, M PETRI, PATRICIA LAMB, M NATTRASS, B L PENTECOST \\ From the General Hospital, Birmingham
}

SUMMARY A review of the records of 353 diabetic patients after a myocardial infarction confirmed the high mortality associated with the condition. The influence of improved diabetic control achieved by intravenous insulin was assessed in 64 patients and compared with earlier experience in a diabetic control group. The frequency of the major complications of myocardial infarction was unchanged and the death rate in both groups was identical (33\%); even the patients with blood glucose concentrations $>20 \mathrm{mmol} / \mathrm{l}$ on admission failed to benefit. Thus careful control of blood glucose concentrations after myocardial infarction in diabetic patients fails to improve the outcome of this high risk group.

Mortality in diabetic patients after myocardial infarction is almost twice that of patients without diabetes mellitus. ${ }^{2}$ Improved metabolic control in the immediate period after infarction might reduce infarct size and influence survival. Insulin enhances the uptake of glucose, the major energy substrate of ischaemic myocardium, ${ }^{3}$ and reduces non-esterified fatty acid concentrations, ${ }^{4}$ which have been suggested to increase infarct size (by increasing myocardial oxygen consumption ${ }^{56}$ ), reduce myocardial contractility, ${ }^{57}$ and be associated with postinfarction arrhythmias. ${ }^{8}$

The aim of this study, therefore, was to determine whether the use of intravenous insulin reduced mortality in diabetic patients after a myocardial infarction. A group of patients treated in this way was compared with a control group comprising all diabetic patients admitted from 1967 to the beginning of the insulin infusion regimen in 1981. To discover whether changes in management had appreciably altered mortality over this period the death rate in all non-diabetic patients was calculated.

\section{Patients and methods}

A retrospective survey of all non-diabetic patients having a myocardial infarction admitted to hospital between 1967 and 1983 was performed to detect any

Requests for reprints to Dr DJ Gwilt, Department of Cardiovascular Medicine, East Birmingham Hospital, Bordesley Green East, Birmingham B9 5ST.

Accepted for publication 5 January 1984 changes in inpatient mortality during this period. The criterion for myocardial infarction was the presence of two of the following: $(a)$ a typical history of cardiac ischaemic pain, $(b)$ a rise in aspartate aminotransferase activity to greater than twice the normal value, or (c) electrocardiographic changes diagnostic of myocardial infarction.

\section{DIABETIC CONTROL GROUP}

The records of all known diabetics admitted to this coronary care unit with a diagnosis of myocardial infarction between 1967 and 1981 (the onset of the insulin infusion regimen) were then reviewed; these patients comprised the diabetic control group. Previously undiagnosed diabetic patients were excluded from the survey (and also from the analysis of nondiabetic patients). The details sought were the age, sex, previous medical history, duration of diabetes, current diabetic treatment, site of infarct, maximum aspartate aminotransferase activity, blood glucose concentration on admission and at midday on the first two days, details of inpatient treatment, and complications of the infarction and survival.

\section{INSULIN INFUSED GROUP}

The details of the insulin infusion regimen have been reported elsewhere. ${ }^{9}$ Briefly 1 unit of insulin per hour is infused if the blood glucose concentration is between 0 and $8 \mathrm{mmol} / \mathrm{l}, 2$ units of insulin per hour if the concentration is between 8 and $12 \mathrm{mmol} / \mathrm{l}, 4$ units per hour if it is between 12 and $24 \mathrm{mmol} / \mathrm{l}$, and if it is $>24 \mathrm{mmol} / \mathrm{l}$ the infusion rate is adjusted to the needs 
Table 1 Characteristics of the diabetic patients studied

\begin{tabular}{|c|c|c|c|}
\hline & Control group & Insulin infused group & $p$ \\
\hline $\begin{array}{l}\text { Age (yr; mean } \pm \text { SD) } \\
\text { No of men }(\%) \\
\text { No }(\%) \text { of patients with a previous history of }\end{array}$ & $\begin{array}{l}61 \cdot 8 \pm 10 \cdot 1 \\
226(64)\end{array}$ & $\begin{array}{l}62 \cdot 8 \pm 9 \cdot 3 \\
48(75)\end{array}$ & $\begin{array}{l}\text { NS } \\
\text { NS }\end{array}$ \\
\hline $\begin{array}{l}\text { Hypertension } \\
\text { Myocardial infarction } \\
\text { Angina } \\
\text { Duration of diabetes }(y r ; \text { mean } \pm \text { SD) } \\
\text { Site of infarct (No of patients) })^{\star} \text { : }\end{array}$ & $\begin{array}{l}50(14) \\
70(20) \\
118(33) \\
12.9 \pm 9\end{array}$ & $\begin{array}{l}7(11) \\
15(23) \\
12(19) \\
12 \pm 7\end{array}$ & $\begin{array}{l}\text { NS } \\
\text { NS } \\
\text { p }<0.02 \\
\text { NS }\end{array}$ \\
\hline $\begin{array}{l}\text { Site of infarct (No of patients) } \\
\text { Anterior } \\
\text { Posterior and inferior } \\
\text { Maximum aspartate aminotransferase, (IU/; mean } \pm \text { SD) } † \\
\text { No of patients }\end{array}$ & $\begin{array}{l}238 \\
147 \\
327 \pm 687 \\
353\end{array}$ & $\begin{array}{l}42 \\
39 \\
416 \pm 492 \\
64\end{array}$ & $\begin{array}{l}\text { NS } \\
\text { NS } \\
\text { NS }\end{array}$ \\
\hline
\end{tabular}

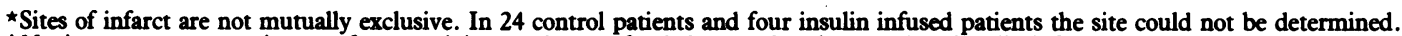
† Maximum aspartate aminotransferase activity was known for 293 control patients and 60 insulin infused patients.

of the individual patient.

All patients known on admission to be diabetic, irrespective of treatment, were treated in this way, and their clinical course and outcome were noted. These patients comprised the insulin infused group.

\section{GLUCOSE AND ENZYME ASSAYS}

The assay for estimating blood glucose concentrations changed in 1978 from one which determined reducing sugar to one which directly assayed blood glucose. Assessment by the department of clinical chemistry had determined that the reducing sugar assay read about $1 \mathrm{mmol} / \mathrm{l}$ higher than the direct method, and this correction factor was applied to the blood glucose values before 1978 to make them compatible. The assay for estimating aminotransferase activity and the range of normal values had not altered appreciably over the period of analysis.

\section{STATISTICAL ANALYSIS}

Results were analysed by Student's $t$ test or the $\chi^{2}$ test as appropriate. The confidence levels of the mortality figures were determined from the binomial distribution.

\section{Results}

\section{NON-DIABETIC MORTALITY}

Between January 1967 and August 1981 (corresponding in time to the control group of diabetic patients) 3261 non-diabetic patients were admitted with a myocardial infarction, of whom $574(17.6 \%)$ died in hospital. From August 1981 to January 1983 (the time of the insulin infused group) a further 341 nondiabetic patients were admitted, and of these 58 $(17.0 \%)$ died, there being no significant difference between the characteristics of the patients admitted

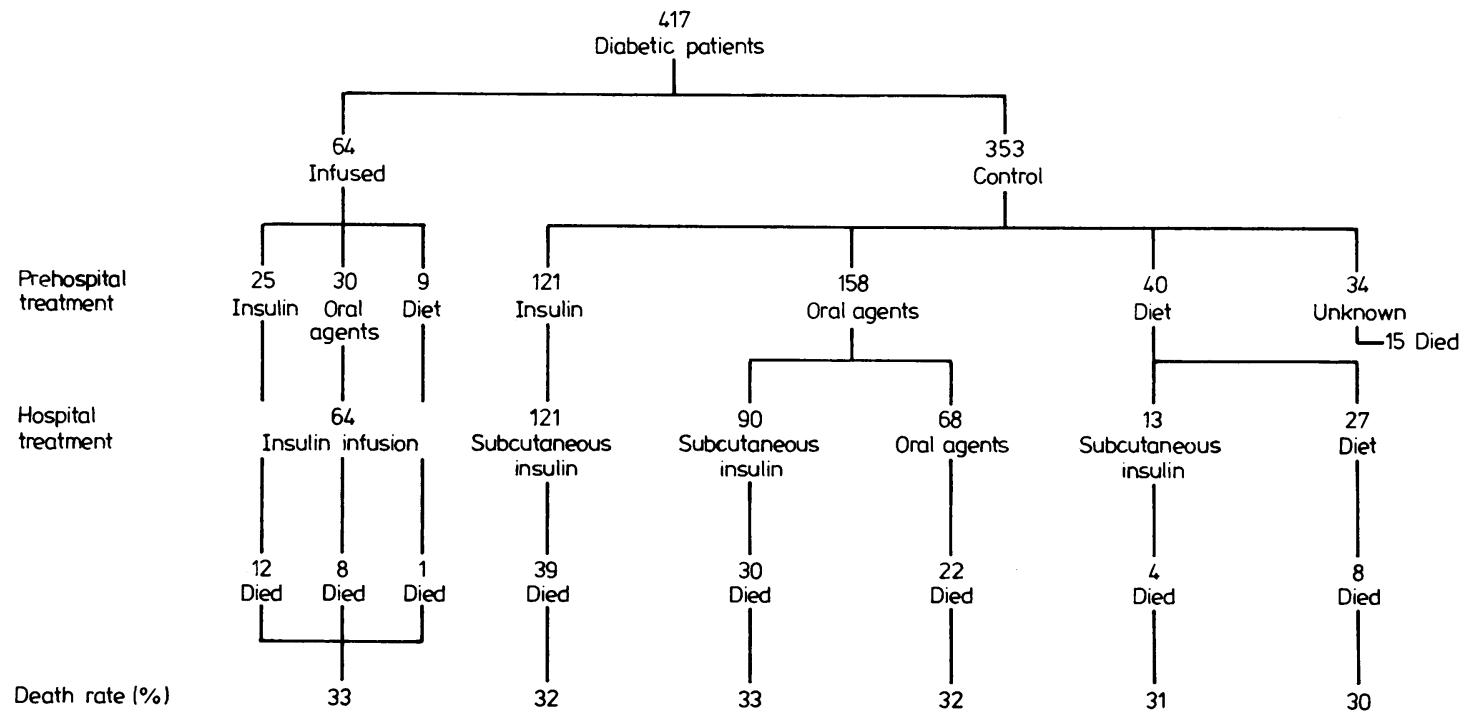

Figure Outcome in 417 diabetic patients after a myocardial infarction. 
Table 2 Complications of myocardial infarction in the two groups of patients

\begin{tabular}{|c|c|c|c|c|c|}
\hline & \multicolumn{2}{|c|}{ Diabetic control group } & \multicolumn{2}{|c|}{ Insulin infused group } & \multirow[t]{2}{*}{ Significance } \\
\hline & No & $\%$ & No & $\%$ & \\
\hline $\begin{array}{l}\text { Haemodynamic complications } \\
\text { Ventricular fibrillation } \\
\text { Complete heart block } \\
\text { Death } \\
\text { No of patients }\end{array}$ & $\begin{array}{l}125 \\
29 \\
40 \\
118 \\
353\end{array}$ & $\begin{array}{l}35 \\
8 \\
11 \\
33\end{array}$ & $\begin{array}{l}30 \\
8 \\
5 \\
21 \\
64\end{array}$ & $\begin{array}{l}47 \\
13 \\
8 \\
33\end{array}$ & $\begin{array}{l}\text { NS } \\
\text { NS } \\
\text { NS } \\
\text { NS }\end{array}$ \\
\hline
\end{tabular}

NS, not significant

during these periods. The years $1967-81$ were divided into periods of three years and the respective death rates were: $1967-9,19.2 \%$; $1970-2,15.7 \% ; 1973-5$, $19.5 \%$; $1976-8,15.6 \%$; and $1979-81,18.7 \%$, there being no statistical difference between any of these groups. Therefore, mortality was unchanged in nondiabetic patients over the study period.

\section{DIABETIC PATIENTS}

Clinical details

The age, sex distribution, diabetic history, and characteristics of myocardial infarction in the diabetic control and insulin infused groups are shown in Table 1 and the Figure. There was no significant difference between the groups in age, sex distribution, previous history (except for angina), prehospital diabetic treatment, duration of diabetes, site of infarct, or maximum recorded values of aminoaspartate transferase activity.

\section{Blood glucose values}

The blood glucose concentrations on admission were similar (the mean $\pm 1 S D$ being $14.6 \pm 8.2 \mathrm{mmol} / \mathrm{l}$ in the control group and $16 \cdot 1 \pm 10.3 \mathrm{mmol} / \mathrm{l}$ in the insulin infused group, the difference not being significant). By midday on the first full day after infarction the mean blood glucose concentration of the insulin infused group was $9.9 \pm 3.6 \mathrm{mmol} / \mathrm{l}$ compared with $12.4 \pm 5.9 \mathrm{mmol} / \mathrm{l}$ for the control group, a difference that was statistically significant $(p<0.01)$.

\section{Outcome}

There was no significant difference between the conventionally treated (control group) and the insulin infused patients in terms of the major complications of myocardial infarction: haemodynamic response (ranging from cardiac failure to cardiogenic shock), complete heart block, or ventricular fibrillation (primary or secondary) (Table 2).

The death rate in the control group was $33 \%$ (118 out of 353 patients) and 33\% (21 out of 64 patients) in the insulin infused group. Clearly, there is no difference between these values, and the $95 \%$ confidence levels are $\pm 12 \%$. If the population mortality is $33 \%$ (based on the 353 control diabetic patients) then the maximum reduction in mortality that might be missed by chance at the $2.5 \%$ level is $36 \%$. Of the 118 deaths in the control group, 110 were due to cardiac failure and eight to some other cause (five to strokes, two to renal failure, and one to bronchopneumonia); in the insulin infused group 20 died in cardiac failure and one as a result of a stroke.

It was thought possible that the benefit of insulin infusion might be restricted to those with high blood glucose concentrations on admission, but no such advantage was shown when the patient population was stratified according to the concentrations on admission (Table 3).

The total experience of managing diabetes over 16 years shows that the death rate remained constant from 30 to $33 \%$ whatever the treatment used (Figure). For the insulin infused group, only the total death rate was computed, since the subsets divided according to prehospital treatment were too small for individual analysis.

\section{Discussion}

The death rate in diabetic patients who have a myocardial infarction is higher than for nondiabetics. ${ }^{2}$ In part this may be due to changes that occur before infarction. Diabetic patients have more extensive coronary atheroma ${ }^{10-12}$ and so might be expected to have more extensive infarcts. A specific cardiomyopathy ${ }^{1314}$ has been reported in diabetes, and this may impair left ventricular function, which adds to the damage induced by infarction. Furthermore, some patients have an autonomic neuropathy, and the changed pain perception may alter the time taken to contact a doctor; moreover, the tachycardia of autonomic neuropathy could increase myocardial oxygen consumption.

It is possible, however, that the metabolic changes induced at the time of infarction may also be of importance. The oxidation of non-esterified fatty acids is the major energy source of the normal myocardium, but ischaemic heart muscle depends largely on the anaerobic metabolism of glucose. ${ }^{3}$ The supply of glucose is partly curtailed by the infarction, 15 such that in diabetic patients, with residual insulin secretion, 
Table 3 Relation between death rate and blood glucose concentrations on admission in the two groups of patients

\begin{tabular}{llll}
\hline & Death rate $(\%)$ & Significance \\
\cline { 2 - 4 } & Diabetic control group & Insulin infused group & \\
\hline $\begin{array}{llll}\text { Blood glucose concentration } \\
(\text { mmol/ }):\end{array}$ & & & NS \\
$0-10$ & $18 / 74(24)$ & $5 / 19(26)$ & NS \\
$10-20$ & $37 / 114(32)$ & $8 / 29(28)$ & NS \\
$>20$ & $23 / 46(50)$ & $7 / 14(50)$ & \\
\hline
\end{tabular}

NS, not significant

the increased output of adrenaline ${ }^{16}$ may inhibit insulin release, while the raised concentrations of glucagon ${ }^{17}$ and cortisol ${ }^{18}$ may cause insulin resistance. Both mechanisms result in high blood glucose concentrations but a reduced cellular supply of glucose.

High concentrations of circulating non-esterified fatty acids are found after myocardial infarction. ${ }^{3415}$ It has been suggested that they increase myocardial oxygen consumption 56 and therefore may increase infarct size, compounding the effect of reduced glucose availability. Furthermore, high fatty acid concentrations may cause reduced contractility 7 and increased frequency of arrhythmias. ${ }^{8}$ It would, therefore, seem possible that good metabolic control, by improving the glucose supply and reducing fatty acid concentrations, might reduce the mortality of myocardial infarction.

Little direct evidence exists to support this hypothesis, but a parallel is present with the use of glucose-insulin-potassium infusion. For many years it has been known that glucose and insulin can improve cardiac function, 1920 and considerable interest arose from the suggestion of Sodi-Pallares $e t a l$, that glucose-insulin-potassium solutions reduce postinfarction arrhythmias. ${ }^{21}$ More recent work has suggested that infarct size in animals may be reduced 2223 and that pump function in man may be improved. ${ }^{4}$ Translating this into the use of insulin for diabetic patients after infarction would suggest that intravenous insulin might be beneficial.

In this study the mortality of non-diabetic patients with myocardial infarction did not alter over the study period (1967-83), and it, therefore, seemed reasonable to take a historical group comprising all diabetic patients admitted from 1967 to 1981 to compare with the insulin group. When the insulin infused and control groups are assessed there is no reduction in the hospital death rate. Furthermore, when patients are subdivided according to their blood glucose concentration on admission (Table 3 ) even those with the highest concentrations, who presumably are most likely to benefit from insulin infusion, show no improvement in prognosis. When the total diabetic sample is reviewed (Figure) the mortality remains constant at about $33 \%$ irrespective of the method of treatment used. Finally, the haemodynamic complication rate (Table 2), the major predictor of outcome, had remained unchanged by the introduction of intravenous insulin. All these observations point to the same conclusion: survival in diabetic patients after myocardial infarction is not dependent on the excellence (or otherwise) of diabetic control.

The confidence levels of the diabetic mortality results are such that a reduction in mortality of $36 \%$ might just be missed by chance (at the $2.5 \%$ level), but in view of all the other observations pointing to the lack of improvement with intravenous insulin the likely benefit that might be missed must be much less.

The inability of good control to alter survival may be due to a number of factors. Firstly, it is possible that if a coronary artery is occluded then insulin also will be unable to reach the infarcted area and so improve the influx of glucose into these cells. Secondly, lipolysis is extremely sensitive ${ }^{24}$ to inhibition by insulin, and so, although non-esterified fatty acid concentrations will fall after insulin infusion, they may fall as quickly after subcutaneous insulin or the use of oral agents. Thirdly, it is probable that the high death rate in diabetic patients may be due to large myocardial infarcts, and then manipulation of cellular metabolism may have only a minor effect on outcome. It is also possible that our insulin regimen is still inadequate, as the mean blood glucose concentration in these patients does not fall within the normal nondiabetic range. Finally, the proportion of men in both diabetic groups was high, unlike the equal sex distribution usually seen in the diabetic population after a myocardial infarction, ${ }^{2} 12$ raising the possibility that local referral patterns may differ from the norm and so influence outcome.

The management of the diabetic patient after infarction remains debatable. Although a reduction in mortality has not been shown with intravenous insulin, it is possible that less easily detectable benefitssuch as reduction in infarct size-might occur; in addition, this insulin protocol provides a simple and effective way of controlling the inevitable dislocation of diabetic metabolism that occurs after myocardial infarction. For these reasons intravenous insulin infusion is used for the management of diabetic patients after coronary occlusion in our hospital. 
We thank the physicians at the General Hospital, Birmingham, for allowing us to study their patients, and gratefully acknowledge the unstinted help of our nursing colleagues.

\section{References}

1 Soler NG, Bennett MA, Pentecost BL, Fitzgerald MG, Malins JM. Myocardial infarction in diabetics. $Q \mathcal{F}$ Med 1975; 44: 125-32.

2 Opie LH, Tansey MJ, Kennelly BM. The heart in diabetes mellitus Part II. Acute myocardial infarction and diabetes. S Afr Med F 1979; 56: 256-61.

3 Liedtke AJ. Alterations of carbohydrate and lipid metabolism in the acutely ischemic heart. Prog Cardiovasc Dis 1981; 23: 321-36.

4 Rackley CE, Russell RO Jr, Rogers WJ, Mantle JA, McDaniel HG, Papapietro SE. Clinical experience with glucose-insulin-potassium therapy in acute myocardial infarction. Am Heart f 1981; 102: 1038-49.

5 Liedtke AJ, Nellis S, Neely JR. Effects of excess free fatty acids on mechanical and metabolic function in normal and ischemic myocardium in swine. Circ Res 1978; 43: 652-61.

6 Vik-Mo H, Mjos OD. Influence of free fatty acids on myocardial oxygen consumption and ischemic injury. Am $\mathcal{F}$ Cardiol 1981; 48: 361-5.

7 Kjekeshus JK, Mjøs OD. Effect of free fatty acids on myocardial function and metabolism in the ischemic dog heart. $f$ Clin Invest 1972; 51: 1767-76.

8 Oliver MF, Kurien VA, Greenwood TW. Relation between serum-free-fatty acids and arrhythmias and death after acute myocardial infarction. Lancet 1968; i: 710-5.

9 Gwilt DJ, Nattrass M, Pentecost BL. Use of low-dose insulin infusions in diabetics after myocardial infarction. Br Med F 1982; 285: 1402-4.

10 Vigorito C, Betocchi S, Bonzani G, et al. Severity of coronary artery disease in patients with diabetes mellitus. Angiographic study of 34 diabetic and 120 non-diabetic patients. Am Heart f 1980; 100: 782-7.

11 Dortimer AC, Shenoy PN, Shiroff RA, et al. Diffuse coronary artery disease in diabetic patients. Fact or fiction? Circulation 1978; 57: 133-6.

12 Root HF, Bland EF, Gordon WH, White PD. Coronary atherosclerosis in diabetes mellitus. $\mathcal{F A M A} 1939$; 113: 27-30.

13 Regan TJ, Lyons MM, Ahmed SS, et al. Evidence for cardiomyopathy in familial diabetes mellitus. $\mathcal{f}$ Clin Invest 1977; 60: 885-99.

14 Hamby RI, Zoneraich S, Sherman L. Diabetic cardiomyopathy. FAMA 1974; 229: 1749-54.

15 Olesen KH, Faergeman O. Metabolic response to acute myocardial infarction. FPEN 1980; 4: 157-9.

16 Benedict CR, Grahame-Smith DG. Plasma adrenaline and noradrenaline concentrations and dopamine- $\beta$ hydroxylase activity in myocardial infarction with and without cardiogenic shock. Br Heart f 1979; 42: 214-20.

17 Hutcheson D, Faloona GR, Leshin SJ, Unger RH, Willerson JT. Serum glucagon and insulin levels and their relationship to blood glucose values in patients with acute myocardial infarction [Abstract]. Circulation 1973; 47-48: (suppl 4): 179.

18 Bailey RR, Abernethy MH, Beaven DW. Adrenocortical response to the stress of an acute myocardial infarction. Lancet 1967; i: 970-3.

19 Visscher MB, Müller EA. The influence of insulin upon the mammalian heart. F Physiol (Lond) 1927; 62: 341-8.

20 Bayliss LE, Müller EA, Starling EH. The action of insulin and sugar on the respiratory quotient and metabolism of the heart-lung preparation. F Physiol (Lond) 1928; 65: 33-47.

21 Sodi-Pallares D, Testelli MR, Fishleder BL, et al. Effects of an intravenous infusion of a potassiumglucose-insulin solution on the electrocardiographic signs of myocardial infarction. Am f Cardiol 1962; 9: 166-81.

22 Maroko PR, Libby P, Sobel BE, et al. Effect of glucoseinsulin-potassium infusion on myocardial infarction following experimental coronary artery occlusion. Circulation 1972; 45: 1160-75.

23 Dalby AJ, Bricknell OL, Opie LH. Effect of glucoseinsulin-potassium infusions on epicardial ECG changes and on myocardial metabolic changes after coronary artery ligation in dogs. Cardiovasc Res 1981; 15: 588-98.

24 Schade DS, Eaton RP. Dose response to insulin in man: differential effects on glucose and ketone body regulation. F Clin Endocrinol Metab 1977; 44: 1038-53. 